\title{
GPPS-BJ-2019-0049
}

\section{An Advanced Method for Processing Compressor Model in Application of Performance Simulation}

\author{
Dai, Hao \\ AECC Commercial Aircraft \\ Engine Co.,LTD \\ cat_paradox@sina.com \\ Shanghai, China
}

\author{
Nikolaidis, Theoklis \\ Cranfield University \\ t.nikolaidis@cranfield.ac.uk \\ Cranfield University, UK
}

\author{
Ju, Luo \\ AECC Commercial Aircraft \\ Engine Co.,LTD \\ sukiska@163.com \\ Shanghai, China
}

\section{ABSTRACT}

A new methodology named Compressor Division is proposed for performance simulation use. Thermodynamic principles and characteristics processing technique are the foundation of this method. The main strategy of Compressor Division method is to divide an integral compressor module into several sub-modules, and solve each of the sub-modules by specific algorithm for obtaining performance information of each individual sub-module. The compressor characteristic is processed as a kind of dividable map and cycle parameters are derived with corresponding equations.

One of the advantages of the Compressor Division method is that the performance simulation process of the gas turbine can be improved, especially when the inter-stage performance of a compressor needs to be solved. In application, engineers can use this method to solve the air bleed performance of a compressor. Compared with conventional methods, multiple sub-modules are created leading to more cycle parameters to be obtained from the airbleeding compressor. As the result, the performance features of the air-bleeding compressor can be comprehensively analysed. Meanwhile, this method has a good adaptability in programming/software applications. Some attempts have been made in those related software for updating algorithm.

Key words: Performance Simulation, Compressor Division, Cycle Parameter, Compressor Map

\section{INTRODUCTION}

In most cases, some aero-dynamical optimizations of compressor performance can be achieved when desirable amount of air bleed takes place in the compressor. Usually, negative effects such as a reduction on thermal efficiency will occur in the gas turbine engine because the energy is wasted to compress the air, but on the other hand, some positive influence such as boundary layer optimization takes place, which can results in an increase of the compressor efficiency. ${ }^{[1]}$

Engine performance simulation is a key step during the whole period of turbine engine design. Conventionally, the engine components were processed as a complete module. Engine performance can be derived based on conventional modules, but the details is impossible to be obtained at interstages.

The new approach is called Compressor Division method. This new method is more flexible than conventional approaches and can be applied to solve both the steady and transient problems. In this paper, only those problems of steady conditions are discussed.

The main idea of this new methodology is to divide the original compressor model into several sub-compressors. Each sub-compressor is an individual model and the cycle parameters can be solved individually by specific algebra.

Off-design (OD) performance simulation of a gas turbine engine usually relies on the information which is obtained from characteristics of components. After the design-point (DP) cycle parameters being confirmed, a specific map processing technique is required to enable the OD simulation for the new engine modules.

\section{BACKGROUND THEORIES}

During the air-compressing process, gas properties such as air temperature or air density are regarded as variables along the stages. Engineers define these phenomena of the air as "compressible flows". Transformed gas state equations can be applied to describe the cycle parameters.

$$
\frac{P_{2}}{P_{1}}=\left(\frac{T_{2}}{T_{1}}\right)^{\frac{C_{p}}{R}}=\left(\frac{T_{2}}{T_{1}}\right)^{\frac{\gamma}{\gamma-1}}=\left(\frac{\rho_{2}}{\rho_{1}}\right)^{\gamma}
$$

Polytropic efficiency is defined as the isentropic efficiency of each infinitesimally stage in the component. ${ }^{[1]}$ According to the definition, its mathematical expression can be written as: 


$$
\eta_{p}=\frac{d T_{i s}}{d T}
$$

Though, the definition of $\eta_{p}$ indicates the polytropic efficiency is originally set to describe the thermal property of a fundamental compression unit/stage, after processing, it is also able to define the thermal properties of the complete compressor. ${ }^{[1]}$

$$
\begin{gathered}
\mathrm{ds}=\mathrm{C}_{p} \frac{d T}{T}-R \frac{d P}{P} \\
\mathrm{C}_{p} \frac{d T_{i s}}{T}=R \frac{d P}{P} \\
\frac{d T}{T} / \frac{d P}{P}=\frac{R}{\mathrm{C}_{p} \cdot \eta_{p}}=\frac{C_{p}-C_{v}}{C_{p} \cdot \eta_{p}}=\frac{\gamma-1}{\gamma \cdot \eta_{p}} \\
T R=(P R)^{\frac{\gamma-1}{\gamma \cdot \eta_{p}}}
\end{gathered}
$$

According to $2^{\text {nd }}$ law of thermodynamics, Eqn.3 can be derived and applied to describe those simple compressible substances. If the thermal process is isentropic, $\mathrm{ds}=0$ and Eqn.4 can be therefore derived. Rearrange Eqn.4, we can obtain Eqn.5. By logarithm calculation, Eqn.6 can be finally derived. Meanwhile, polytropic efficiency can also be applied for determining isentropic efficiency, as Eqn.7 shows.

$$
\eta_{\text {is }}=\frac{\text { real work done }}{\text { ideal work done }}=\frac{(P R)^{\frac{\gamma-1}{\gamma}}-1}{(P R)^{\frac{\gamma-1}{\gamma \cdot \eta}}-1}=\frac{T R^{\eta p_{-1}}}{T R-1}
$$

Heat capacity can be regarded as a function of temperature. To find an equivalent heat capacity $\bar{C}_{\mathrm{p}}$ in a compression system, Eqn. 8 is required. ${ }^{[2]}$

$$
\overline{C_{p}}=\frac{\int_{T_{1}}^{T_{2}} C_{p} d T}{T_{2}-T_{1}}
$$

Where $T_{2}$ is outlet temperature and $T_{1}$ is inlet temperature of the compression system.

\section{METHODOLOGY}

Now, we can choose to treat the compressor model whether to be a "complete body" or a dividable part. If there is a position designed for compressor bleed, we can divide the original compressor model into two parts, as fig. 1 shows.

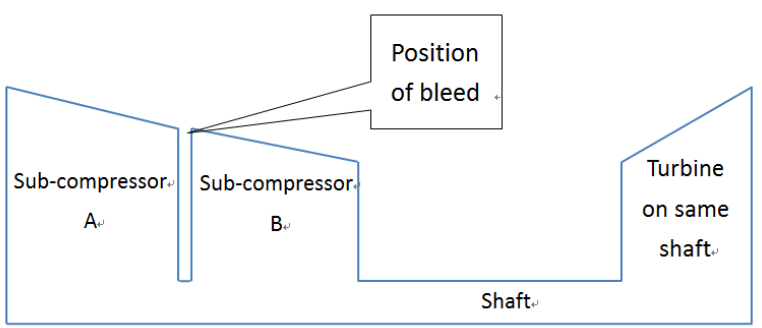

Figure 1 Compressor Model Division

In fact, the core idea of compressor separation is to achieve a "model reconstruction". After separation process, the compressor now can be regarded as two individual parts. Some design parameters such as rotational speed are same for both sub-compressors, but the other properties such as pressure ratio or isentropic efficiency should be redefined in each individual sub-compressor.

\section{Assumptions}

Before the algebra section, three assumptions should be made at first. They are:

a) Flow field has no significant changes during the OffDesign air bleed process, thus the original compressor map can still be applied without any modification;

b) Polytropic efficiency on each stage is remains unchanged during Design-Point simulation;

c) Temperature rise $\Delta \mathrm{T}$ can be set as a constant during the Design-Point performance simulation if the temperature distribution in compressor is not specified.

Polytropic efficiency is a fundamental property in a compressor. Relying on engineering experience, the polytropic efficiency can be set as a constant along the whole compressor. Similarly, relying on the design data from some existing engines, it is a good approximation to set temperature rise as a constant along the compressor as well.

\section{Algebra}

Start from the given compressor inlet cycle parameter, pressure ratio, and isentropic efficiency, compressor inlet and outlet total temperature $\left(\mathrm{T}_{\text {in }}, \mathrm{T}_{\text {out }}\right)$ and total pressure $\left(\mathrm{P}_{\text {in }}, \mathrm{P}_{\text {out }}\right)$ can be derived. Based on cycle parameters, the first step of compressor model division is to determine the polytropic efficiency of the compressor. Relying on Eqn. 6 and Eqn. 7, we can rearrange them and define new expressions.

$$
\begin{gathered}
\eta_{p}=\frac{(\gamma-1) \cdot \log _{T R}(P R)}{\gamma} \\
\left.\eta_{p}=\frac{\gamma-1}{\gamma \log _{P R}\left(\frac{P R}{\eta_{i s}^{\frac{\gamma-1}{\gamma}}}-1\right.}+1\right)
\end{gathered}
$$

Either Eqn. 9 or Eqn. 10 can be used to derive polytropic efficiency of the compressor. Since we have presumed the polytropic efficiency as an unchanged parameter along the whole stages of the compressor, after separation, the polytropic efficiency can directly be introduced into new models of sub-compressors.

If the temperature distribution is not specified in the original compressor, we can use assumption c) to find temperature $\mathrm{T}_{\mathrm{b}}$ of bleed air.

$$
T_{b}=\frac{n_{b}}{n_{t}} \times\left(T_{\text {out }}-T_{\text {in }}\right)+T_{\text {in }}
$$

In Eqn. (11), $\mathrm{n}_{\mathrm{b}}$ is the stage number where air is extracted; $\mathrm{n}_{\mathrm{t}}$ is total stage number.

$$
\begin{gathered}
T R_{A}=\frac{T_{b}}{T_{\text {in }}}=\frac{n_{b}}{n_{t}} \times \frac{\left(T_{\text {out }}-T_{\text {in }}\right)}{T_{\text {in }}}+1 \\
T R_{B}=\frac{T_{\text {out }}}{T_{b}}
\end{gathered}
$$

After determining the bleed air temperature $T_{b}$ via laws of linear interpolation, the temperature ratio $T R_{A}$ and $T R_{B}$ in sub-compressor A and sub-compressor B can be found by Eqn. (12) and Eqn. (13).

$$
\eta_{i s, A}=\frac{T R_{A}^{\eta_{p}-1}}{T R_{A}-1}
$$




$$
P R_{A}=\left[\left(T R_{A}-1\right) \eta_{i s, A}+1\right]^{\frac{\gamma}{\gamma-1}}=\left(T R_{A}\right)^{\frac{\gamma \cdot \eta_{p}}{\gamma-1}}
$$

The next step is to find PR and $\eta_{\text {is }}$ for subcompressors. Eqn. (14) and Eqn. (15) are in common use for both sub-compressor A and sub-compressor B. Performancerelated parameters have been derived out during the separation process. This is the last step of the model division. If all of the new sub-compressors' parameters have been derived out, model reconstruction is completed.

Similar as the condition with only one bleed offtake position involves, the idea of compressor division can be applied into the conditions with multiple air offtake occur on different stages.

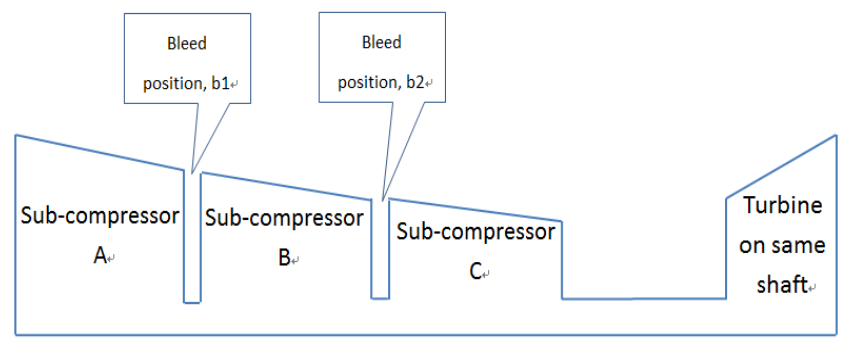

\section{Figure 2 Compressor Model Division When Multiple} Positions of Compressor Bleed Occur

As fig. 2 indicates, if there are two positions of air bleed on a compressor, we need to divide the compressor into three individual sub-modules. Referring the Eqn. (11), now the bleed air temperature $T_{b 1}$ can be derived as Eqn. (16) shows.

$$
T_{b 1}=\frac{n_{b 1}}{n_{t}} \times\left(T_{\text {out }}-T_{\text {in }}\right)+T_{\text {in }}
$$

Similarly, all values of the bleed air temperature $T_{b 2}$, $T_{b 3}, \ldots, T_{b X}$ can be derived via Eqn. (16). Use Eqn. (12) or Eqn. (13) to find temperature ratio for each sub-compressor. Isentropic efficiency and pressure ratio of sub-compressors' can be derived according to Eqn. (14) and Eqn. (15). And model reconstruction can be completed via repeating these steps.

The algebra introduced above has fully described the processing strategy for DP conditions. For OD simulations, an additional processing technique is required - it is Compressor Characteristic Disassembly technique.

\section{Compressor characteristic processing method}

The basic issue of compressor characteristic processing is to disassemble the original compressor map and create new maps for describing all sub-compressors. Thus, a common approach is to disassemble the original characteristic map into $\mathrm{X}$ respective maps. $\mathrm{X}$ is the number of sub-compressors. Non-dimensional values on $\mathrm{X}$-axis and $\mathrm{y}$-axis of each map should be redefined.

Currently, reallocating pressure ratio and rescaling nondimensional mass flow for each individual sub-compressor to determine non-dimensional values is the simplest way to process the maps. The value of PR on each sub-compressor can be obtained via Eqn. (15) at the model reconstruction stage.

Figure 3 is an example of compressor map dissembling. The original model comes from a high pressure compressor
(HPC) on a three-shaft engine. Assuming there is one bleed position at middle stages of the compressor, the figure 3(b) and 3(c) can be a map processing result.

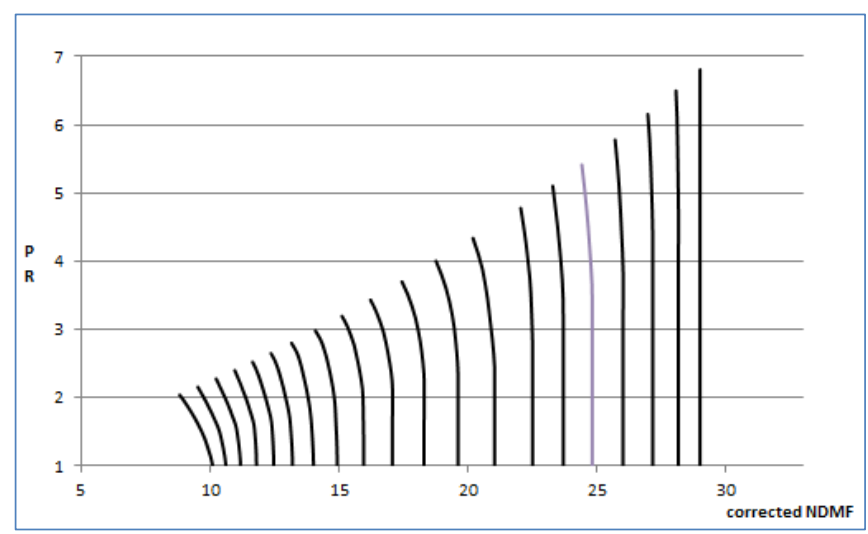

(a) Original map

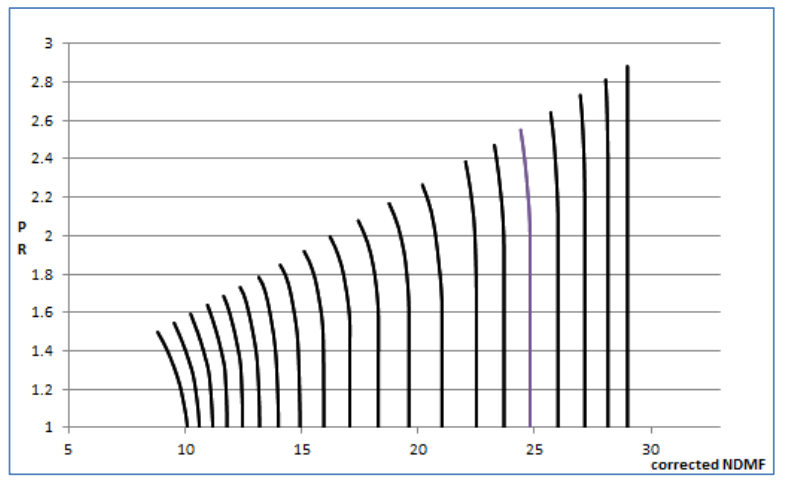

(b) Processed map of sub-compressor A

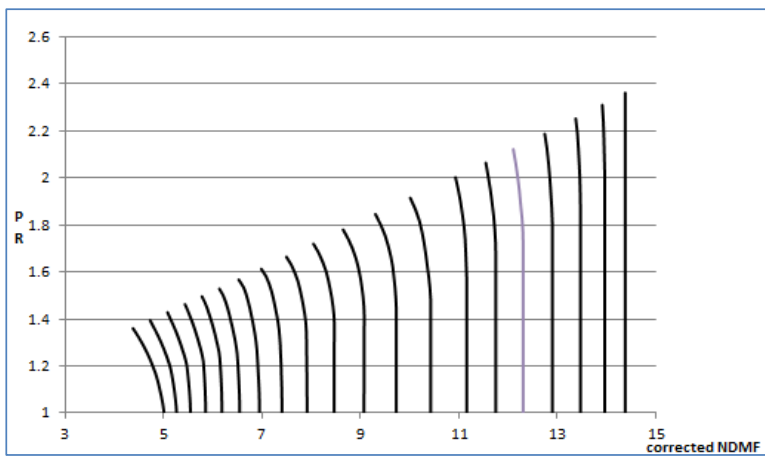

(c) Processed map of sub-compressor B

Figure 3 Example of Compressor Map Disassembly

PR can be directly derived from model reconstruction steps. The corrected NDMF (non-dimensional mass flow) values for two maps are defined as:

$$
\begin{gathered}
\mathrm{NDMF}_{A}=\frac{W_{\text {in }} \cdot \sqrt{\frac{T_{b}}{T_{\text {in }}}}}{\frac{P_{b}}{P_{\text {in }}}} \\
\mathrm{NDMF}_{B}=\frac{\left(W_{\text {in }}-W_{b}\right) \cdot \sqrt{\frac{T_{\text {out }}}{T_{b}}}}{\frac{P_{\text {out }}}{P_{b}}}
\end{gathered}
$$

Now, the next step is to use the derived non-dimensional numbers PR and corrected NDMF for determining scaling factors. Eqn. (19), Eqn. (20) and Eqn. (21) are expressions for NDMF scaling factor $\mathrm{WASF}_{A}, \mathrm{PR}$ scaling factor $\mathrm{PRSF}_{A}$, and $\eta_{i s}$ scaling factor ETASF $_{A}$ correspondingly. 


$$
\begin{aligned}
\mathrm{WASF}_{A} & =\frac{\mathrm{NDMF}_{A}}{\mathrm{NDMF}_{\text {old }}} \\
\mathrm{PRSF}_{A} & =\frac{\mathrm{PR}_{A}-1}{\mathrm{PR}_{\text {old }}-1} \\
\mathrm{ETASF}_{A} & =\frac{\mathrm{ETA}_{A}}{\mathrm{ETA}_{\text {old }}}
\end{aligned}
$$

Commonly, compressor maps are created by discrete points. The next step is to multiply each point with scaling factors to form new maps. Figure 4 is an example of scaling of compressor map. ${ }^{[3]}$

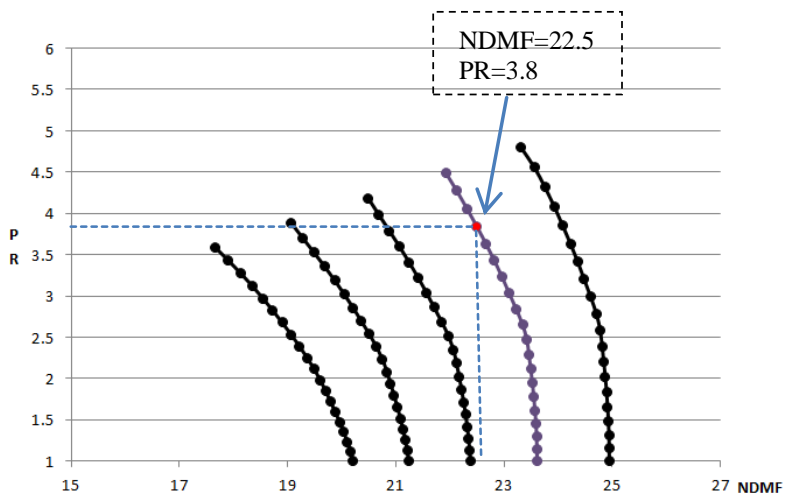

(a) Original compressor map

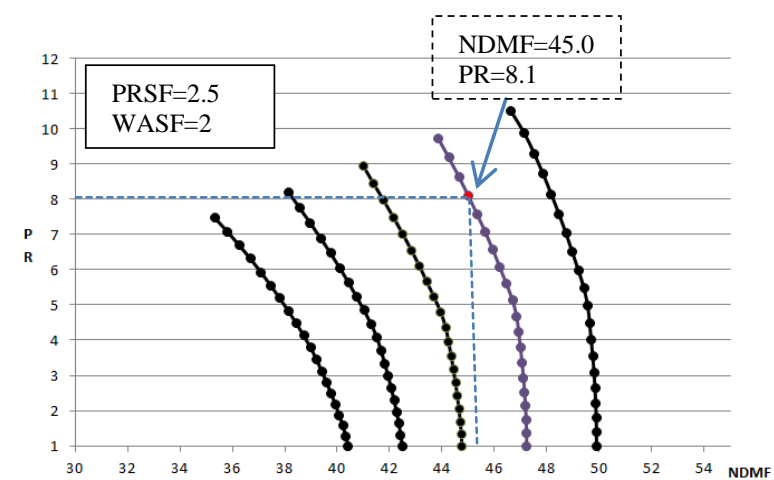

(b) Compressor map after scaling

Figure 4 Map Scaling

In figure 4, NDMF and PR are equal to 22.5 and 3.8 correspondingly for DP condition on original compressor map. The given information in fig. 4(b) are $\mathrm{NDMF}=45$ and $\mathrm{PR}=8.1$ for the new compressor on DP condition. Thus, the scaling factor can be found as $\mathrm{PRSF}=2.5$ and $\mathrm{WASF}=2$ for the new map, and subsequently figure 4(b) can be plotted.

Since all of the discrete points have been multiplied with scaling factors, there will be no change on "shape" between two maps. In fact, the scaling results solved via this technique only can provide an ideal solution. Since we have assumed the temperature rise is a constant along the stages, we can therefore, approximately consider the stage properties to be similar for all of the stages. So this "undeforming" phenomenon can be regarded as a desirable solution.

\section{Flow chart}

Fig. 5 displays the steps of model processing for those compressors with bleed. All of the steps of the advanced have been included.

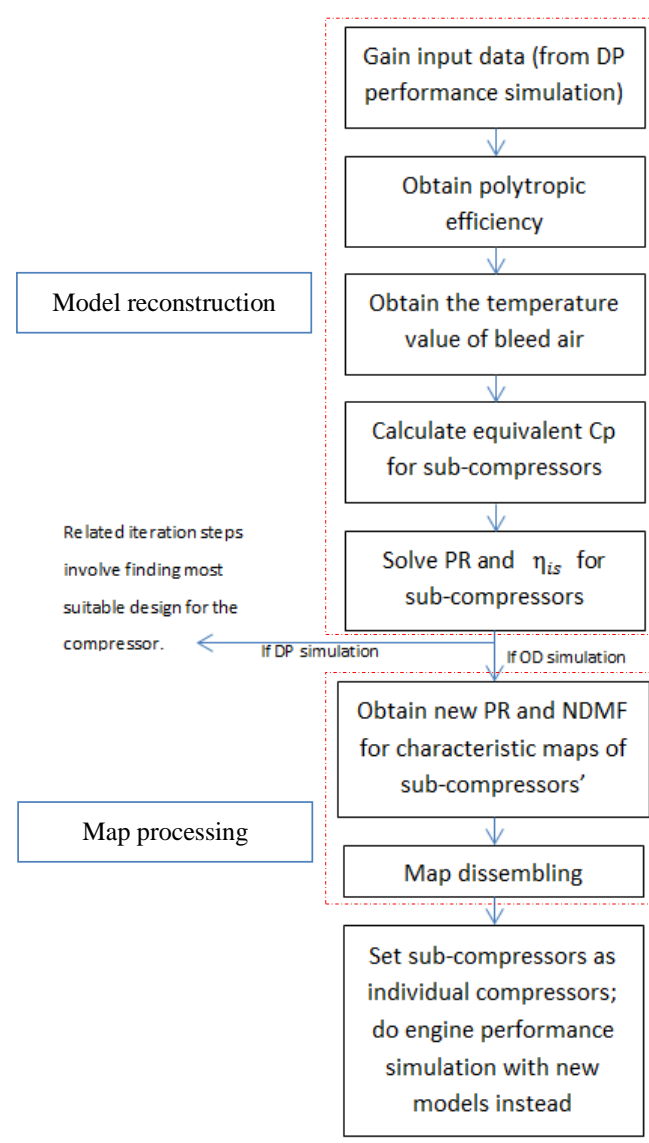

Figure 5 Flow Chart of Procedure of Compressor Division Method

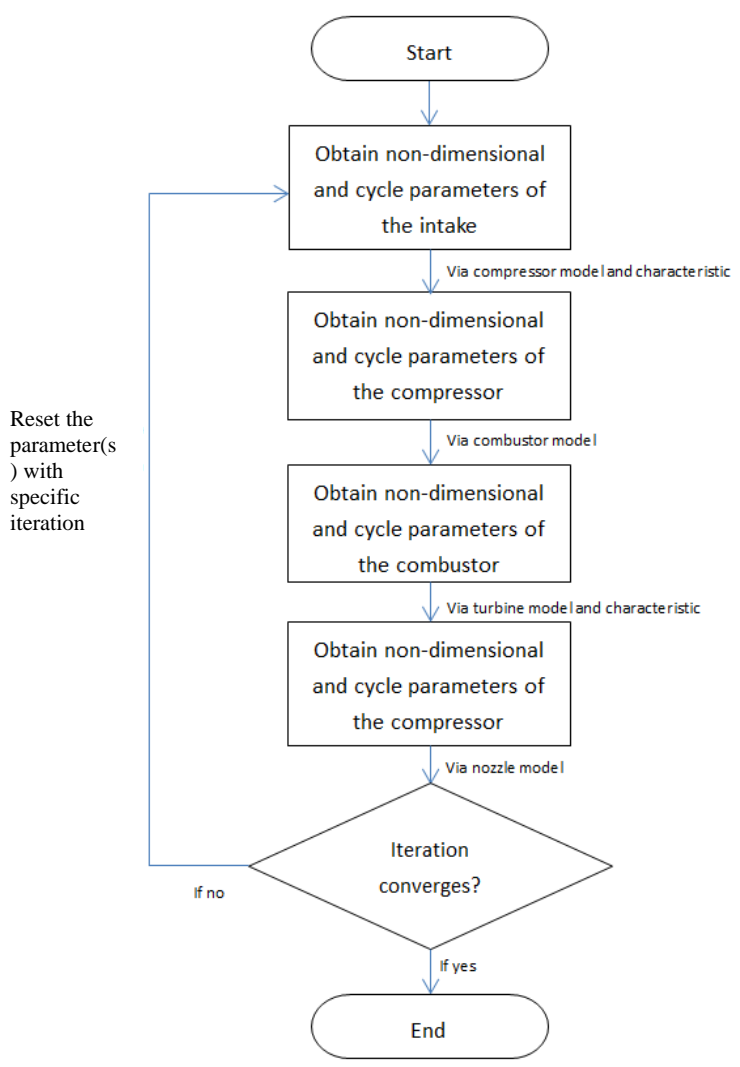

(a) Conventional computation procedures of gas turbine engine performance 


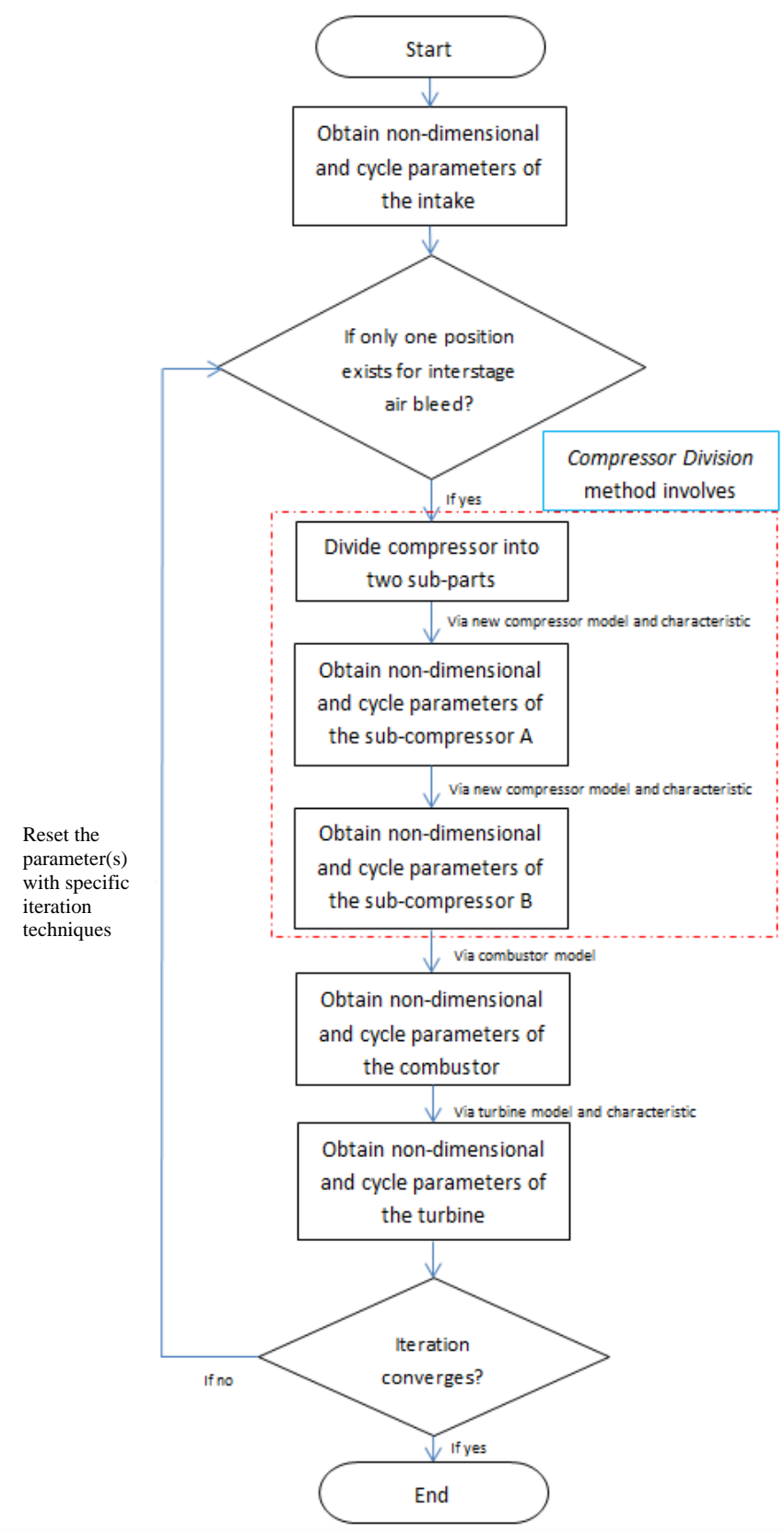

(b) New computation procedures of gas turbine engine performance simulation

\section{Figure 6 Flow Charts for the Gas Turbine Engine Simulation}

Fig. 6 shows key simulation procedures of a gas turbine engine. The Compressor Division method can directly insert into and replace the original compressor model.

\section{RESULTS AND DISCUSION}

To specify the advantage of Compressor Division method, a compressor model with inter-stage bleed is divided into two parts for investigating air bleed performance.

Simulation results in Fig.7 shows the operation line of both the sub-compressors when only one bleed position exists on middle of the compressor and bleed air mass is 5\% of compressor's incoming flow.

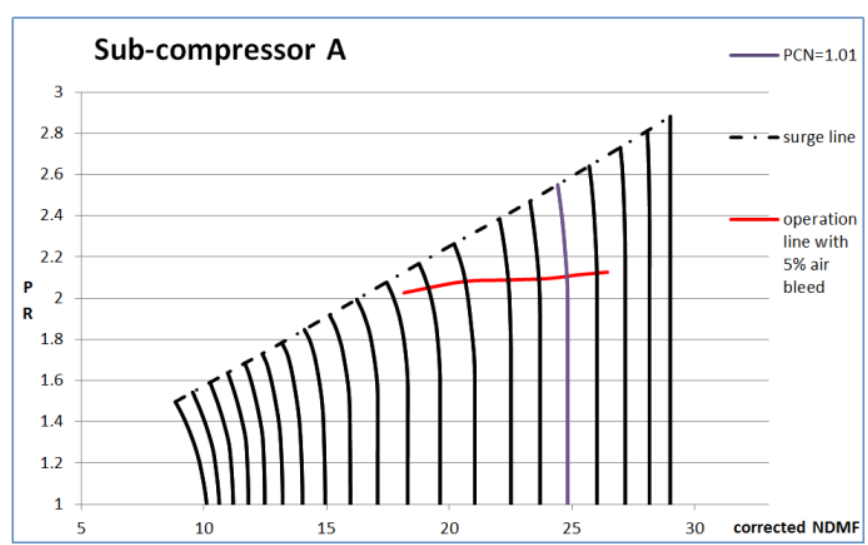

(a) Map for sub-compressor A (upstream side)

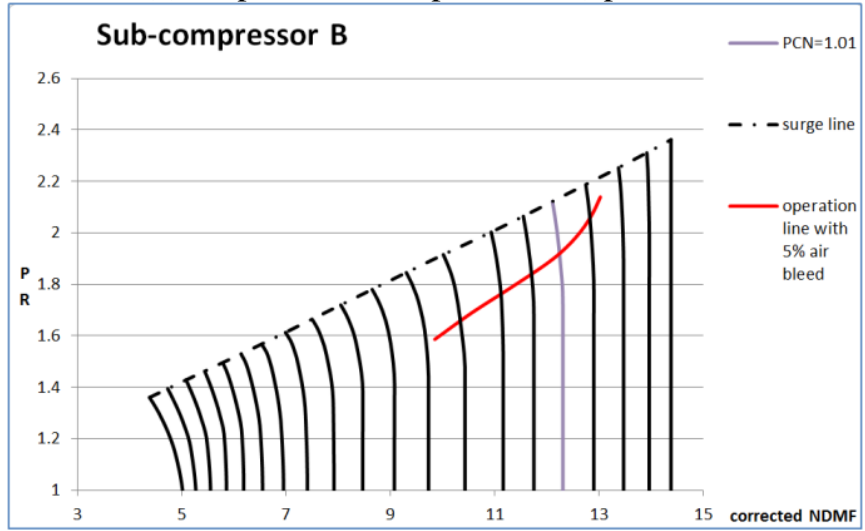

(a) Map for sub-compressor B (downstream side)

\section{Figure 7 Individual Maps for Sub-compressors}

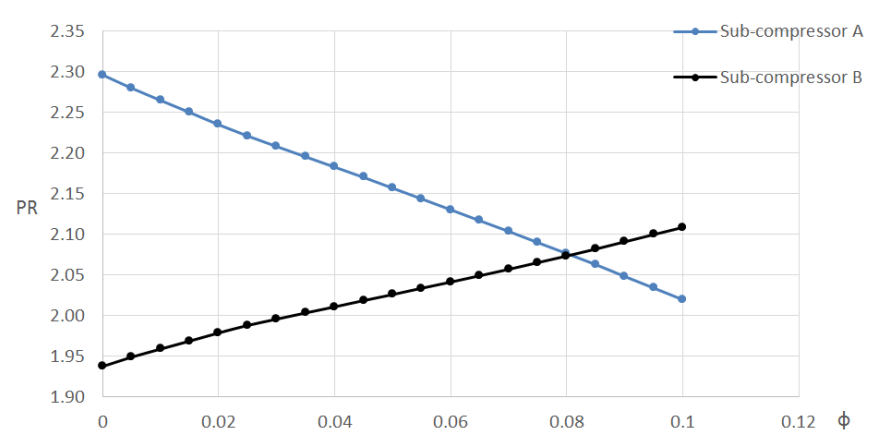

Figure 8 Effect of Different Air Bleed Ratio

In Fig.7, when a compressor bleed occurs, the frontal stages have more risks to stall if the dimensionless rotation speed (PCN) is less than $100 \%$ of its design value. However, if rotation speed is larger than $100 \% \mathrm{PCN}$, the surge margin increases instead.

At the downstream side of the bleed valves, the operation features are different. Surge margin increase when rotation speed is lower than $100 \% \mathrm{PCN}$ and stall risk decreases when rotation speed exceeds $100 \%$ PCN. Fig. 7 has clearly indicated the operation features are opposite for both sub-compressor modules. 
Fig. 8 shows the tendency of the change of PR for both sub-compressors. The air bleed position is on the middle of the compressor. PR is reduced on upstream side of the compressor but rises on downstream side when the mass flow of extracted air is increasing. For a brief conclusion, the results indicate that, with an increasing amount of air bleed, the risk of choke at frontal side of the compressor is decreased and blockage effect will decrease at tailing side of the compressor. The inter-stage bleed can bring positive effects for compressor performance, if the flow field have no significant change.

Data in Fig. 7 and Fig. 8 are taken from the computation results when Compressor Division method involves in. In this case, if we refuse to apply this new method, details in both upstream and downstream modules will be more difficult to be obtained.

\section{CONCLUSIONS}

The new methodology Compressor Division is a set of improved algorithm for gas turbine performance simulation. Compared with conventional methods, Compressor Division method can provide additional information for demonstrating compressor performance at different parts of the compressor. As one of the advantages, the researchers can investigate the performance details at each individual part of the upstream or downstream sub-modules by applying the new method, and therefore, some detailed mechanisms can be discovered and studied.

In addition, this methodology can be introduced into application of engine control applications and may play essential roles in it.

\section{NOMENCLATURE}

$\begin{array}{lll}\mathrm{Cp} & {[\mathrm{J} \cdot(\mathrm{kg} / \mathrm{K})]} & \text { Specific heat capacity } \\ \gamma & {[-]} & \text { Heat capacity ratio } \\ \eta_{p} & {[-]} & \text { Polytropic efficiency } \\ \eta_{i s} & {[-]} & \text { Isentropic efficiency } \\ \phi & {[-]} & \text { Air bleed ratio }\end{array}$

\section{ABBREVIATIONS}

PR

TR

ETA

NDMF

DP

OD

HPC

PRSF

ETASF

NDMFSF

PCN

\section{ACKNOWLEDGMENTS}

The authors gratefully acknowledge the conscientious education in Cranfield University (UK) and support provided by the AECC Commercial Aircraft Engine Co., Ltd.

\section{REFERENCES}

[1] Pilidis, P. and Prof. Palmer, J.R., Gas Turbine Theory and Performance $[M]$, School of Aerospace, Transport and Manufacturing (SATM), Cranfield University.

[2] Shen, W.D. and Tong, J.G., Thermodynamics Application in Engineering ( $5^{\text {th }}$ edition), published by Beijing Education press (2016), ISBN: 978-7-04-044632-6.

[3] Nikolaidis, T. and Pachidis, V., Gas Turbine Theory and Performance $[M]$, School of Aerospace, Transport and Manufacturing (SATM), Cranfield University.

[4] Chu, W., Liu, Q., Hu, C., p.114 (2009) Aeronautics Turbomachinery, Northwestern Polytechnical University, ISBN 9787561226193 